Laporan Penelitian

\title{
Perbandingan efektivitas beberapa pelarut terhadap serumen obturans secara in vitro di Makassar
}

\author{
*Syahrijuita, **Sutji Pratiwi Rahardjo, **Nani Iriani Djufri, **Riskiana Djamin \\ * Bagian Biokimia \\ **Bagian Telinga Hidung Tenggorok - Kepala Leher \\ Fakultas Kedokteran Universitas Hasanuddin, Makassar
}

\begin{abstract}
ABSTRAK
Latar belakang: Serumen obturans merupakan suatu keadaan patologis yang tidak membahayakan jiwa tetapi dapat mengakibatkan rasa penuh di telinga, nyeri, gangguan pendengaran dan ketulian serta penurunan kualitas hidup. Tujuan: Penelitian ini bertujuan untuk mengetahui perbandingan efektivitas enam pelarut yaitu aquadest, $\mathrm{NaCl} 0,9 \%$, minyak kelapa, minyak zaitun, karbogliserin $10 \%$ dan sodium dokusat $0,5 \%$ terhadap serumen obturans secara in vitro serta untuk mengetahui lama waktu kontak yang paling efektif suatu pelarut terhadap kelarutan serumen. Metode: Penelitian ini merupakan eksperimental laboratorium dengan menggunakan 30 spesimen serumen obturans yang telah dipadatkan dengan berat masing-masing 40mg. Kelarutan serumen diukur menggunakan spektofotometer Spectronic 21. Perbandingan efektifitas pelarut diuji dengan menggunakan uji One Way Anova dengan alfa $<0,05$. Hasil: Didapatkan hasil bahwa efektivitas pelarut yang berbeda bermakna didapatkan pada menit ke-20, ke-25 dan ke-30 hanya antara aquadest dan $\mathrm{NaCl}$ 0,9\% terhadap minyak kelapa dan minyak zaitun menggunakan spektofotometer. Waktu kontak yang efektif secara in vitro adalah $\geq 20$ menit dan cenderung meningkat sampai batas 30 menit. Pada menit ke-20 dan ke-25, $\mathrm{NaCl}$ 0,9\% merupakan pelarut paling efektif sedang pada menit ke-30 paling efektif adalah aquadest. Minyak zaitun dan minyak kelapa merupakan pelarut yang efektivitasnya paling rendah. Kesimpulan: Pelarut berbasis air lebih efektif dibanding pelarut berbasis lemak.
\end{abstract}

Kata kunci: Pelarut serumen, serumen obturans, in vitro

\section{ABSTRACT}

Background: Cerumen obturans is a pahtological condition which is not harmful to the patients but could cause ear numbness sensation, earache, hearing impairment, deafness and decreasing the quality of life. Purpose: The objective of the study was to compare the effectiveness of six solvents, which were aquadest, $\mathrm{NaCl} 0,9 \%$, coconut oil, olive oil, carboglycerin $10 \%$ and sodium docusate 0,5\% againts cerumen obturans by means of in vitro study and to know the most effective contact duration of a solvent to liquefy cerumen. Method: The study is a laboratory experimental by using 30 specimens of solid cerumen, each weight $40 \mathrm{mg}$. The cerumen liquefaction was measured by Spectronic 21 spectrophotometer. The effectiveness of the solvents were tested with One Way Anova with alfa $<0,05$. Result: The spectrophotometer showed significant differentiations of effectiveness of the solvents in the $20^{\text {th }}, 25^{\text {th }}$ and $30^{\text {th }}$ minutes, only in aquadest and $\mathrm{NaCl} 0,9 \%$ againts coconut oil dan olive oil. The effective duration of contact by in vitro study was $\geq 20$ minutes and tend to increase up till 30 minutes. In the $20^{\text {th }}$ and $25^{\text {th }}$ minutes, $\mathrm{NaCl} 0,9 \%$ was the most effective solvent, while aquadest was most effective in the $30^{\text {th }}$ minutes. Olive oil and coconut oil are less effective solvents. Conclusion: Water-based solvents were found more effective than lipid-based solvents. 
Key words: cerumen solvents, cerumen obturans, in vitro

Alamat korespondensi: Nani Iriani Djufri, Bagian Telinga Hidung Tenggorok - Kepala Leher, Fakultas Kedokteran Universitas Hasanuddin, Makassar. email: irianidjufri@yahoo.com

\section{PENDAHULUAN}

Serumen adalah hasil produksi kelenjar sebasea dan kelenjar serumenosa yang terdapat di kulit sepertiga luar liang telinga. Dalam keadaan normal serumen dapat keluar sendiri saat mengunyah atau menelan tanpa kita sadari. Serumen menimbulkan masalah bila terjadi serumen obturans yaitu suatu keadaan patologis dari serumen, serumen menumpuk dan menjadi keras, suatu keadaan yang walaupun tidak membahayakan jiwa tetapi dapat mengakibatkan rasa penuh di telinga, nyeri, gangguan pendengaran dan ketulian serta penurunan kualitas hidup. ${ }^{1,2}$

Serumen obturans mempunyai prevalensi yang cukup tinggi dan bisa mengenai semua umur. Serumen obturans merupakan salah satu dari 10 penyakit terbanyak di Poliklinik THT RS.Dr. Wahidin Sudirohusodo Makassar. Hasil penelitian dari Farida Muhammad ${ }^{3}$ melaporkan 2.015 orang dari 7.184 orang, atau sekitar $28 \%$ murid SD yang telah dilakukan pemeriksaan pada 14 SD di Makassar menderita serumen obturans.

Ada berbagai cara mengeluarkan serumen antara lain dengan menggunakan kait telinga, cara pembilasan, pemberian serumenolitik maupun kombinasi antara ketiganya. ${ }^{2.4}$ Dalam kehidupan sehari-hari, masyarakat umum menggunakan berbagai bahan untuk mengurangi keluhan telinga tersumbat akibat serumen tersebut, antara lain dengan meneteskan air ( $\mathrm{H} 2 \mathrm{O})$, minyak goreng (minyak kelapa), olive oil (minyak zaitun) dan lain-lain dengan tujuan agar dapat melunakkan serumen yang keras dan padat sehingga dengan mudah dapat dikeluarkan dari telinga. Bahanbahan yang digunakan tersebut masih perlu penelitian untuk membuktikan manfaat dan khasiatnya secara ilmiah. Selain itu, $\mathrm{NaCl} 0,9 \%$ yang merupakan cairan fisiologis sering pula dijadikan kontrol pembanding dalam melakukan uji efektivitas serumenolitik secara in vitro maupun in vivo di luar negeri. ${ }^{5,6}$

Penelitian ini bertujuan untuk mengetahui perbandingan efektivitas enam pelarut yaitu aquadest, $\mathrm{NaCl} 0,9 \%$, minyak kelapa, minyak zaitun, karbogliserin $10 \%$ dan sodium dokusat $0,5 \%$ terhadap serumen obturans secara in vitro serta untuk mengetahui lama waktu kontak yang paling efektif suatu pelarut terhadap kelarutan serumen.

\section{METODE}

Penelitian ini merupakan eksperimental laboratorium dengan menggunakan 30 spesimen serumen obturans yang telah dipadatkan dengan berat masing-masing $40 \mathrm{mg}$. Serumen obturans yang digunakan bukan yang berupa keratosis obturans dan tidak terkontaminasi dengan darah, kapas dan zat lain. Pada penelitian ini digunakan 30 spesimen serumen yang berasal dari 11 serumen obturans dengan berat $\geq 250 \mathrm{mg}$, berwarna coklat kehitaman dan konsistensinya keras dan padat serta dapat dibagi menjadi 6 spesimen dengan berat masing-masing $40 \mathrm{mg}$. Spesimen serumen yang digunakan dalam penelitian ini mengalami modifikasi berupa pemadatan dan pencetakan ulang menggunakan tabung silinder berdiameter $0,5 \mathrm{~cm}$ yang bertujuan menghilangkan bias akibat perbedaan bentuk, ukuran dan konsistensinya. Setiap enam spesimen yang dipakai untuk membandingkan efektivitas berasal dari serumen yang sama dan dilarutkan masing-masing dalam $2 \mathrm{ml}$ aquadest, $\mathrm{NaCl} 0,9 \%$, minyak kelapa, minyak zaitun, karbogliserin $10 \%$ dan sodium dokusat $0,5 \%$. Dilakukan pengulangan 5 kali dengan menggunakan spesimen yang berasal dari empat serumen obturans yang lain. Kelarutan serumen diukur menggunakan spektrofotometer Spectronic 21. ${ }^{7}$ Perbandingan efektifitas pelarut diuji dengan menggunakan uji One Way Anova dengan alfa $<0,05$. 


\section{HASIL}

Didapatkan hasil bahwa terdapat perbedaan bermakna secara analisis one way anova terhadap efektivitas beberapa pelarut pada menit ke-20 ( $\mathrm{p}=0,03)$, menit ke-25 $(\mathrm{p}=0,02)$ dan menit ke-30 $(\mathrm{p}=0,011)$. Uji lanjut dengan Post Hoc Test dengan menggunakan spektrofotomotor Spectronic 21, menunjukkan adanya perbedaan bermakna efektivitas pelarut terhadap serumen obturans hanya antara aquadest dan $\mathrm{NaCl} 0,9 \%$ terhadap minyak kelapa dan minyak zaitun. Hasil rerata kelarutan keenam pelarut berdasarkan lama watu kontak dari menit ke-5 sampai menit ke-30 dapat dilihat pada tabel 1.

Dari tabel di atas dapat diketahui rerata efektivitas kelarutan serumen obturans dalam aquadest, $\mathrm{NaCl}$ 0,9\%, minyak kelapa, minyak zaitun, karbogliserin $10 \%$ dan sodium dokusat $0,5 \%$ yang menunjukkan peningkatan kelarutan serumen seiring dengan peningkatan lama waktu kontak.

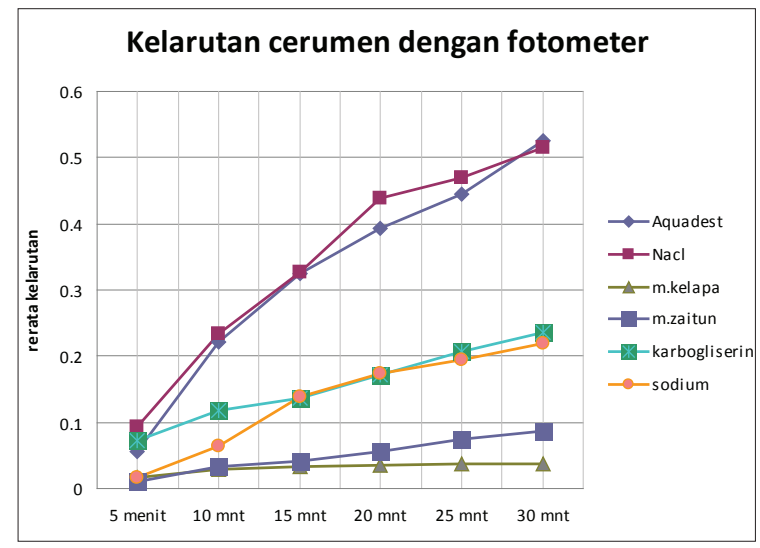

Grafik 1. Perbandingan efektitivitas beberapa pelarut terhadap kelarutan serumen obturans secara in vitro di Makassar.
Dari grafik di atas terlihat bahwa $\mathrm{NaCl}$ 0,9\% dan aquadest merupakan pelarut serumen yang paling efektif. Minyak kelapa dan minyak zaitun merupakan pelarut yang efektivitasnya paling rendah. Efektivitas karborbogliserin 10\% dan sodium dokusat $0,5 \%$ terletak antara keduanya atau dengan kata lain memiliki efektivitas yang sedang.

Aquadest dan $\mathrm{NaCl} 0,9 \%$ yang merupakan pelarut berbasis air memilki efektivitas kelarutan yang lebih baik dibandingkan karbogliserin $10 \%$ dan sodium dokusat $0,5 \%$, minyak zaitun dan minyak kelapa yang merupakan pelarut berbasis lemak.

Pada penelitian ini didapatkan lama waktu kontak yang efektif terhadap kelarutan serumen obturans secara in vitro adalah adalah $\geq 20$ menit dan cenderung meningkat sampai batas 30 menit. Pada menit ke-20 efektivitas serumenolitik dari yang tertinggi berturut-turut yaitu $\mathrm{NaCl} 0,9 \%$, aquadest, sodium dokusat, karbogliserin $10 \%$, minyak zaitun dan minyak kelapa, dan pada menit ke-25 efektivitas serumenolitik dari yang tertinggi berturut-turut adalah $\mathrm{NaCl} 0,9 \%$, aquadest, karbogliserin $10 \%$, sodium dokusat $0,5 \%$, minyak zaitun dan minyak kelapa, sedangkan pada menit ke-30 yang terbaik efektivitas kelarutannya berturut-turut adalah aquadest, $\mathrm{NaCl} 0,9 \%$, karbogliserin $10 \%$, sodium dokusat $0,5 \%$, minyak zaitun dan minyak kelapa.

\section{DISKUSI}

Penelitian ini mendapatkan efektivitas pelarut berdasarkan lama waktu kontak menggunakan spektofotometer pada menit ke-20 dan ke-25

Tabel 1. Perbandingan efektitivitas beberapa pelarut terhadap kelarutan serumen obturans secara in vitro di Makassar

\begin{tabular}{lrrrrrr}
\hline \multirow{2}{*}{ Pelarut } & \multicolumn{6}{c}{ Rerata absorban kelarutan serumen (nm) } \\
\cline { 2 - 7 } & 5 menit & 10 menit & 15 menit & 20 menit & 25 menit & 30 menit \\
\hline Aquadest & 0.0568 & 0.2214 & 0.3252 & 0.3930 & 0.4444 & 0.5246 \\
NaCl 0,9\% & 0.0924 & 0.2346 & 0.3272 & 0.4378 & 0.4696 & 0.5156 \\
M.kelapa & 0.0170 & 0.0296 & 0.0326 & 0.0348 & 0.0364 & 0.0382 \\
M.zaitun & 0.0108 & 0.0324 & 0.0414 & 0.0552 & 0.0750 & 0.0866 \\
Karbogliserin & 0.0722 & 0.1170 & 0.1364 & 0.1710 & 0.2062 & 0.2362 \\
S.dokusat & 0.0166 & 0.0650 & 0.1378 & 0.1732 & 0.1948 & 0.2198 \\
\hline
\end{tabular}


yang paling efektif adalah $\mathrm{NaCl} 0,9 \%$. Pada menit ke-20 menunjukan absorban 0,43780 nm sedangan untuk menit ke-25, $\mathrm{NaCl} 0,9 \%$ menunjukkan absorban 0,46960 nm. Adapun untuk menit ke-30 yang paling efektif adalah aquadest dengan absorban $0,52460 \mathrm{~nm}$.

Hasil efektivitas pelarut yang didapatkan pada penelitian ini berbeda dengan hasil penelitian Made Leli Rahayu ${ }^{8}$ yang menunjukan daya larut paling tinggi terhadap serumen obturans adalah hidrogen peroksida 3\% $(0,23867 \mathrm{~nm})$ disusul aquadest $(0,08417 \mathrm{~nm})$, sodium dokusat $(0,08017 \mathrm{~nm})$, olium kokos $(0,01600 \mathrm{~nm})$ dan karbogliserin $10 \%(0,01050 \mathrm{~nm})$. Hal ini dimungkinkan karena pada penelitian tersebut Made Leli Rahayu menggunakan serumen yang tidak dipadatkan ulang dengan berat hanya 10 mg dan menggunakan beberapa pelarut yang berbeda pula.

Aquadest (air) merupakan pelarut universal dan tidak mengubah $\mathrm{pH}$ larutan oleh karena sifatnya yang netral. ${ }^{9}$ Pada penelitian ini aquadest merupakan pelarut paling efektif dibanding ke lima pelarut lain pada menit ke-30. Mengingat harganya murah dan mudah diperoleh, aquadest dapat menjadi alternatif serumenolitik. Hasil penelitian ini juga membenarkan hasil yang telah dilaporkan sebelumnya oleh Bellini ${ }^{10}$ bahwa aquadest merupakan serumenolitik yang lebih efektif dari yang lainnya, dan juga penelitian Robinson dan Hawke ${ }^{11}$ menunjukkan bahwa air sebagai serumenolitik sama efektifnya dengan sodium dokusat $0,5 \%$.

Adapun $\mathrm{NaCl}$ 0,9\% yang merupakan larutan isotonis dan biasanya digunakan sebagai bahan infus, sering pula digunakan sebagai kontrol dalam penelitian in vitro maupun in vivo. Pada penelitian ini $\mathrm{NaCl}$ 0,9\% menunjukkan efektivitas terbaik pada menit ke-20 dan ke-25. Hal ini mendukung hasil penelitian terdahulu bahwa $\mathrm{NaCl} 0,9 \%$ merupakan serumenolitik yang sama baiknya dengan Cerumenex (trietanolamin polipeptida dan oleat kondensat 10\%) dan Murine (karbamide peroksida 6,5\%) menurut penelitian Rolland ${ }^{12}$ secara in vivo.
Pada aquadest dan $\mathrm{NaCl}$ 0,9\% kadar air yang dikandungnya mengakibatkan hidrasi sel keratin yang selanjutnya dapat menginduksi keratolisis sehingga terjadi disintegrasi bolus serumen, sedangkan minyak zaitun dan minyak kelapa merupakan pelarut yang paling kurang efektif terhadap serumen obturans. Hal ini diduga akibat fungsi minyak yang cenderung sebagai pelembut dan tidak mengakibatkan disintegrasi dari bolus serumen. Walaupun demikian minyak zaitun dan minyak kelapa merupakan pelarut lemak yang tersedia di rumah tangga, mudah didapat dan relatif aman sehinga dapat dipakai sebagai alternatif serumenolitik.

Karbogliserin $10 \%$ dan sodium dokusat $0,5 \%$ efek serumenolitiknya berada antara aquadest dan $\mathrm{NaCl}$ 0,9\% dengan minyak zaitun dan minyak kelapa. Hal ini sesuai dengan penelitian Bellini ${ }^{10}$ yang menunjukkan bawa efektivitas serumenolitik sodium dokusat berada antara air dan minyak zaitun.

Karbogliserin 10\% merupakan serumenolitik yang mengandung gliserin yang digunakan sebagai pelarut lemak sekaligus mengandung air, sehingga efektifitasnya lebih baik dari sodium dokusat $0,5 \%$ tetapi lebih rendah dari air dan $\mathrm{NaCl} 0,9 \%{ }^{13}$

Semakin lama waktu kontak dengan suatu pelarut semakin besar kelarutan serumen obturans terbukti dalam penelitian ini .Berdasarkan hasil yang dapat dilihat pada tabel dan grafik di atas dapat dijelaskan lama waktu kontak yang efektif suatu pelarut terhadap serumen obturans minimal 20 menit, dan bila waktu kontaknya lebih dari 20 menit menunjukkan semakin tinggi tingkat kelarutan yang terjadi sampai batas waktu 30 menit. Berdasarkan hasil tersebut dapat direkomendasikan lama waktu kontak efektif untuk serumenolitik dalam pelayanan THT adalah minimal 20 menit.

Kelemahan pada penelitian ini adalah bahwa hasil efektivitas beberapa pelarut berdasarkan penelitian in vitro, sehingga untuk dapat melakukan aplikasi langsung pada pasien perlu sebelumnya dilakukan penelitian secara in vivo. Hal ini 
penting mengingat kelarutan serumen secara in vivo dipengaruhi oleh beberapa faktor antara lain: anatomi liang telinga, luas permukaan serumen obturans yang kontak dengan serumenolitik, dosis dan teknik/cara pemberiannya, sehingga memiliki lebih banyak keterbatasan dibandingkan aplikasi in vitro, walaupun terbuka kesempatan melakukan modifikasi yang tidak terbatas

Dari penelitian ini dapat disimpulkan bahwa terdapat perbedaan bermakna efektivitas antara aquadest dan $\mathrm{NaCl} 0,9 \%$ terhadap minyak kelapa dan minyak zaitun namun tidak terdapat pebedaan bermakna efektivitas di antara pelarut yang lain. Efektivitas pelarut terhadap serumen obturans dengan menggunakan spektrofotometer meningkat seiring dengan peningkatan lama waktu kontak. Waktu kontak yang efektif secara statistik dengan $\mathrm{p}<0,05$ adalah $\geq 20$ menit sampai batas waktu 30 menit. Secara in vitro pelarut berbasis air lebih efektif dibandingkan pelarut berbasis lemak. Oleh karena penelitian ini masih bersifat in vitro perlu dilakukan penelitian lebih lanjut efektivitas beberapa pelarut tersebut terhadap kelarutan serumen obturans secara in vivo. Penelitian ini juga merekomendasikan lama waktu kontak efektif sebuah serumenolitik dalam pelayanan THT adalah minimal 20 menit.

\section{DAFTAR PUSTAKA}

1. Guest.JF, Greener.MJ, Robinson AC, Smith AF. Impacted cerumen: composition, production, epidemiology and management. Q.J. Med 2004 ; 97(8):477-88.

2. Sosialisman, Alfian, Helmi. Kelainan telinga luar. Dalam: Soepardi EA, Iskandar N, Bashiruddin J, Restuti RD, Eds. Buku Ajar THT-KL. Edisi ke-6. Jakarta: Balai Penerbit FKUI. hal 57-63
3. Muhammad F.Faktor-faktor yang mempengaruhi prevalensi otitis media pada murid sekolah dasar di Makassar. Thesis. Makassar: Bagian I.K.THT-KL. FK.UNHAS; 2007. hal 5-40

4. Metha AK. An in vitro comparison of the disintegration of human earwax by five ceruminolytic commonly used in general practice. Br J Clin Pract. 1985; 39:200-3

5. Sinclair S. Preferred practice guideline for cerumen management. College of Audiologists and Speechlanguage pathologists of Ontario (CASLPO); 2005. p.17

6. Masterson E, Seaton.TL. How does liquid docusate sodium compare with triethanolamine polypeptide as a ceruminolytic for acute earwax removal?. J Fam Pract St.Louis, Missouri 2000; 49(12):1076

7. Soewotto H, Sadikin M, dkk.. Biokimia Eksperimen Laboratorium Cetakan I. Bagian Biokimia FKUI. Jakarta. 2001.Hal 1-15

8. Rahayu ML. Perbedaan daya larut karbogliserin $10 \%$, hidrogen peroksida $3 \%$, olium kokos, akuades dan natrium dokusat $0,5 \%$ dalam gliserin terhadap serumen obturans (suatu uji in vitro). Thesis. Denpasar: Bagian I.K.THT-KL. FK.Udayana Bali; 2007. hal. 6-50.

9. Eekhof JAH, Bock.GH, Cessie.SL, Springer.MP. A quasi-randomised controlled trial of water as a quick softening agent of persistent earwax in general practice. Br J Clin Pract.2001; 51:635-7.

10. Bellini MJ, Terry RM, Lewis FA. An evaluation of common cerumenolytic agent: an in-vitro study. Blackwell Synergy-Clin Otolaryngol 1989; 14 (1):23-5.

11. Hawke M. Update cerumen and cerumenolytics. Available from : http:/ www. ENT Journal.Com/ search. htm. accessed February 20, 2007.

12. Roland. PS, Smith TL. Clinical practice guideline: cerumen impaction. Am Acad Otolaryngol-Head and Neck Surg Found 2008; 139 (3 suppl2):S1-S21

13. McAuley DF, 2000. How effective is docusate as a cerumenolytic agent? GlobalRPh inc.http:/ www. globalrph.com/ docusate.htm. 02/01/2008 